\title{
People and Bonobos in the Southern Lake Tumba Landscape, Democratic Republic of Congo
}

\author{
Bila-Isia Inogwabini ${ }^{1,2,3^{*}}$, Albert Bankanza Nzala ${ }^{2}$ and Jean Christophe Bokika ${ }^{4}$ \\ ${ }^{I}$ Durell Institute for Conservation and Ecology, University of Kent at Canterbury, UK \\ ${ }^{2}$ WWF DRC, Lac Tumba Program, Democratic Republic of Congo \\ ${ }^{3}$ Swedish University of Agricultural Sciences, Uppsala - Sweden \\ ${ }^{4}$ Mbou-Mon-Tour-Conservation Non-Governmental Organization
}

\begin{abstract}
The southern Lake Tumba landscape is one of the very few areas in the range of the bonobo distribution where the species occurs within distances easily accessible by human populations. It offers exceptional human-bonobo interactivity on which several ecological hypotheses have been tested. Ecological studies carried out in this area indicated that ecological factors cannot, on their own, explain the presence of the bonobos in high density. Detailed studies on human ecology, including how people in the southern Lake Tumba Landscape perceive the presence of the bonobos, are necessary to fully depict ecological interactions between bonobos and their environment in the southern Lake Tumba landscape. Structured interview questionnaires were administered to local people from two ethnic groups within the southern Lake Tumba Landscape and responses were recorded. A $\chi^{2}$-tests undertaken frequencies of responses to examine whether the perceived bonobo presence and abundance differed indicated that, indeed, the Bateke has a great knowledge of the bonobo ecology, they perceived bonobos differently when compared to the Ntomba. They showed greater willingness to protect the species. More generally, we concluded that the willingness to address conservation issues depended on tribe and have historical and cultural roots.
\end{abstract}

Keywords: Bonobos, Bateke, Lake Tumba landscape, conservation

\section{Introduction}

The publication of 'The limits of growths' has stimulated increased interest over the last six decades in exploring the role played by humans in the ecosystems in which they live (Inogwabini \& LeaderWilliams, 2012; Morris, 2000). However, interdisciplinary data have often been lacking to demonstrate inter-relationships between people and wildlife though after years of ecological research on wildlife scientists have to discover that man, more than any other ecological factor, determined the distribution of wildlife (Barnes et al. 1991). The realization of that fact, which has been latent in ecological literature for many years, has brought to the multidisciplinary ecological approaches whereby acquiring knowledge of the social and cultural implications of natural resources for local people became an inevitable component of sound scientific species conservation planning (Boitani, 1995). Previous research (Bennett \& Robinson, 2000; Butynski \& Koster, 1994; Barnes et al., 1991; Gadsby,

*Corresponding author
1990) has shown the importance of local human history, local demographic patterns and different local cultures in shaping human attitudes toward the wildlife with which local people share their land. In turn, such attitudes have been demonstrated to help explain the distribution patterns of large mammals (Lingard et al., 2003), through their influence on such factors as local hunting patterns on, and levels of protection afforded to, wildlife.

Bonobo researchers have always indicated that the species occurred in large numbers in areas where it was tolerated by communities. However, thorough assessment of that assertion has been lacking (Inogwabini \& Leader-Williams, 2012). This paper aims to provide an overview of the cultural background of Lake Tumba Landscape, in order to explain the relationships between human communities and bonobo population. The southern Lake Tumba landscape is one of the very few areas in the bonobo distribution where bonobos are within distances easily accessible by human populations; they literally share the same environment for their respective daily activities. It offers exceptional human-bonobo interactivity where several hypotheses can be tested. 
Therefore, after several ecological studies (Inogwabini et al. 2007a; Inogwabini et al. 2007b; Inogwabini \& Bewa, 2009) carried out in this area, a detailed paper on people's attitudes toward the conservation of the bonobos was necessary to present the first preliminary global picture of the ecological interactions between bonobos and their environment in the southern Lake Tumba landscape. This paper presents answers to the specific questionnaire on how people in the southern Lake Tumba Landscape perceive the presence of the bonobos; it does examine answers to the questionnaire to see if the local population's attitude is correlated with the distribution of the bonobos.

\section{Study site}

The DRC segment of the bi-national Lake Tele- Lake Tumba Landscape is $c a 80,000 \mathrm{~km}^{2}$ and comprises a large range of major freshwater and terra firma habitats and is generally divided between the southern and the northern parts (Inogwabini, 2013). This study was conducted in the southern portion, which covers $\sim 36,270 \mathrm{~km}^{2}$ in DRC, located between $01^{\circ}: 00^{\prime}: 000^{\prime}$ and $03^{\circ}: 00^{\prime}: 00^{\prime}$ 'S , and $17^{\circ} 00^{\prime} 00^{\prime}$ ' and $18^{\circ}: 45^{\prime}: 00^{\prime}$ 'E (Figure 1).

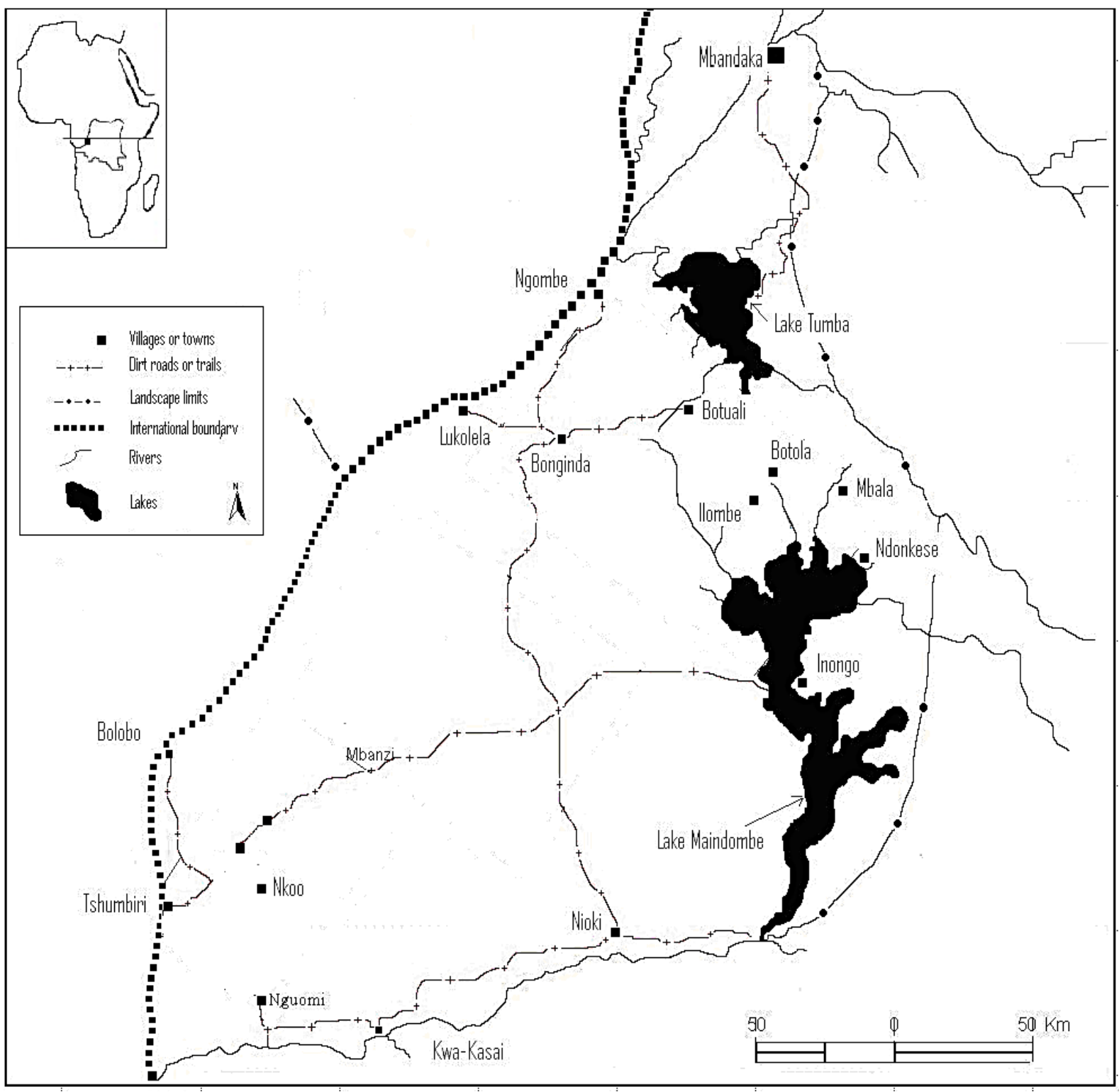

Figure 1. The Southern Lake Tumba Landscape - sources: Inogwabini et al. (2007, a, b) 
The study site is a region with an extensive network of rivers and creeks whose most dominant features are the two lakes (Lakes Tumba and Maindombe). Both lakes are shallow (Corsi, 1984; Bailey, 1986); they are remnants of a much larger interior lake that once occupied the entire Congo Basin in historical times (Peters \& O’Brien, 1999; Anka et al., 2007). The southernmost end of the zone lies on the Bateke Plateau (altitude 280-380 m asl). Mean monthly temperatures averages at $19.5^{\circ} \mathrm{C}$; the mean humidity is between 72 and $85 \%$ annually (Inogwabini et al. 2006). Large assemblages of species are present, of which the endemic bonobos are of the greatest conservation concern. Seven species of other diurnal primates include the Angolan pied colobus Colobus angolensis, Allen's swamp monkey Allenopithecus nigriviridis, black mangabey Lophocebus aterrimus, the Salonga red colobus (Procolobus) Piliocolobus tholonii, the red-tailed monkey Cercopithecus ascanius, the De Brazza's monkey Cercopithecus neglectus and the Wolf's monkey Cercopithecus mona wolfi (Gautier-Hion et al., 1999). Local communities claim that the golden-bellied mangabey Cercocebus chrysogaster was also present near Maindombe, which concurs with the species distribution map compiled by Gautier-Hion et al. (1999) but disappeared some years ago due to hunting (Inogwabini \& Thompson, 2013). Forest elephants Loxodonta africana cyclotis, lion Panthera leo, long thought extinct, and leopards Panthera pardus, forest buffaloes Syncerus cafer nanus and hippopotamuses Hippopotamus amphibious are also present. Rivers and lakes are home to $\sim 120$ fish species (CBFP, 2005), Osborn's dwarf crocodile Osteolaemus tetraspis osborni, the Nile crocodile Crocodylus niloticus and the slender-snouted Crocodylus cataphractus (Inogwabini et al., 2007a; Inogwabini et al. 2007b). Brncic et al. (2007) identified 420 plant species belonging to 79 families, including species that have been previously described as of paramount importance to bonobos for food and nesting trees such as Annonaceae (e.g. Annonidium manii, Greenwayodendron (Polyalthia) suaveolens) and Marantaceae (e.g. Haumania liebrechtsiana, Megaphrynium macrostachyum) (Fruth \& Hohmann, 1994; Badrian \& Malenky, 1984). Ethnographically, the region is complex and supports 11 tribal groups. Six of these (the Basengele; the Bolia; the Bokote; the Ekonda; the Ntomba; the Losakanyi) belong to the larger ensemble of the Mongo and the others include the Bateke; the Batiene; the Baboma; and the Banunu, all cohabiting with the Batswa, a minority ethnic group of pygmy. The Ntomba dominate the territory of Bikoro, which they shared with Bokote, Losakanyi and Batswa (Hulstaert, 1993a,b). The highest population density of 23.9 inhabitants $/ \mathrm{km}^{2}$ occurs in the region surrounding Lake Tumba in the administrative territory of Bikoro. Human population density decreases to a mean of 6.2 inhabitants $/ \mathrm{km}^{2}$ in the more southern territories of Lukolela, Bolobo and Kutu (Inogwabini, 2010).

\section{Methods}

A questionnaire comprising five main sets of questions was administered to local people from two ethnic groups within the southern Lake Tumba Landscape. The main sections comprised questions on: (i) the social and economic background of respondents; (ii) the presence of bonobos in their local area and perceived abundance of the species; (iii) knowledge that local people possess of the ecology of bonobos; (iv) perceptions that local communities hold of bonobos; and (v) perceived levels of threat to the survival of bonobos. Three research assistants administered the questionnaires, took notes and completed the interview forms. To ensure that a good sample of both tribal groups was included in the interviews and focal group discussions, we followed a step-wise approach to the random selection of villages for interviews and focal group discussions. First, a random choice between villages belonging to the Bateke was made. Second, equally, a random choice between villages belonging to the Ntomba was made.

A simple frequency analysis was carried out to determine whether tribal groups differed in their socio-economic background, including: age, level of education, professional activities, and so on. These metrics were later incorporated as explanatory variables in analyses to determine whether differences in the knowledge of, and perceptions towards, bonobos were based on their socioeconomic background. Cut-off points for age classes were chosen to represent the local realities in DRC (Inogwabini et al., 2005; INS 1994), which take into account factors such life expectancy (45 years for males), leaving age for secondary schools (18 years, in principle), and the age of adulthood, the first official first age when citizens can undertake legal work (18 years).

The second step consisted of overlaying maps of different tribal groups on known patterns of bonobo distribution, recorded through surveys (Inogwabini et al. 2007a; Inogwabini \& Leader-Williams, 2012) and during interviews, a step designed to help calibrate results derived from interview surveys. Next, relative frequencies of answers to the questionnaire were calculated. The third step comprised comparing these frequencies using non-parametric statistics. A $\chi^{2}$ test for association (Ennos, 2000; Sokal \& Rohlf, 
1995; Clarke, 1994; Ilersic, 1973), was undertaken depended on tribe and have historical and cultural roots maintaining ethnic group as independent variables, to examine whether the perceived bonobo presence and abundance, the local knowledge of the bonobo ecology, the local perception on bonobos and the willingness to protect bonobos and other conservation issues depended on tribe and have historical and cultural roots. Same test was used, maintaining sex, age groups, education and profession as independent variables, to see if, within a given ethnic or tribal group, the knowledge people possess on the ecology of the bonobos, their perception and their willingness to protect the species depended on different social categories.

\section{Results}

A total of 146 interviews were carried out in 21 villages occupied by the Bateké, while a total of 238 interviews were carried out in 19 villages occupied by the Ntomba (Table 1).

Table 1. Social structures among Bateke $(\mathrm{N}=146)$ and Ntomba $(\mathrm{N}=238)$ respondents

\begin{tabular}{lcclcc}
\hline Age Groups & \multicolumn{2}{c}{ Frequencies } & Education level & \multicolumn{2}{c}{ Frequencies } \\
\hline $0-18$ & Bateke & Ntomba & & Bateke & Ntomba \\
$18-30$ & 0 & 0 & No formal education & 50 & 39 \\
$30-45$ & 28 & 73 & Primary Education & 52 & 85 \\
$45-$ & 44 & 99 & 6 Year Secondary & 39 & 78 \\
& 74 & 66 & 3 Year University & 5 & 23 \\
Total & \multirow{2}{*}{} & 238 & 5 Year University and above & 0 & 13 \\
& 146 & & & 146 & 238 \\
\hline
\end{tabular}

A $\chi^{2}$ test indicated that there was a significant difference between the Bateke and Ntomba demographic structures $\left(\chi^{2}=0.120\right.$; df $=3$ ). Among both Bateke and Ntomba respondents, levels of education varied from no formal education $(34.2 \%$ and $16.3 \%$ respectively), to primary education (35.6\% and $35.7 \%$ respectively), and to secondary education (26.7\% and $32.7 \%$ respectively), while only $3.4 \%$ and $15.0 \%$ (respectively) of respondents had received tertiary. Education levels among respondents from the two tribes differed ( $\chi^{2}=62.64$ $>\mathrm{p}=0.05, \mathrm{df}=4)$, and Ntomba respondents had generally attained better levels of education. Employments among respondents from the two tribes differed $\left(\chi^{2}=74.06>\mathrm{p}=0.05\right.$, df $\left.=4\right)$, and Ntomba respondents had generally more fixed jobs than was the case for Bateke. Interestingly, no Ntomba respondents claimed to be employed by the state, even though the Ntomba had attained better education levels than the Bateke.

Among the Bateke, most $(88.4 \%)$ respondents indicated that bonobos were present in their forests. Furthermore, $74.7 \%$ indicated that they were within a 3-hour walking distance from their village (Table 2), which is equivalent to a $3-5 \mathrm{~km}$ distance in this forested environment. Many $(54.1 \%)$ respondents in the 30-45 year age group thought bonobos were very abundant, while $24.6 \%$ of the same age group thought bonobos were abundant (Table 2).

Table 2 Bonobo presence and perceived abundance by different age groups within the Bateke

\begin{tabular}{|c|c|c|c|c|c|c|c|c|c|c|}
\hline Age (Years) & Presence & \multicolumn{5}{|c|}{ Distance from village (hours) } & \multicolumn{4}{|c|}{ Perceive Abundance } \\
\hline & & $0-3$ & $4-6$ & $7-9$ & $\begin{array}{l}10- \\
12\end{array}$ & $>12$ & $\begin{array}{l}\text { Very } \\
\text { abundant }\end{array}$ & Abundant & Rare & Unknown \\
\hline $18-30$ & $23.0 \%$ & $35.0 \%$ & $11.6 \%$ & $1.4 \%$ & $0.0 \%$ & $0.0 \%$ & $0.0 \%$ & $0.0 \%$ & $0.0 \%$ & $11.6 \%$ \\
\hline $30-45$ & $27.0 \%$ & $19.7 \%$ & $0.0 \%$ & $0.0 \%$ & $0.0 \%$ & $0.0 \%$ & $54.1 \%$ & $24.6 \%$ & $0.0 \%$ & $0.0 \%$ \\
\hline$>45$ & $38.4 \%$ & $20.0 \%$ & $0.0 \%$ & $0.0 \%$ & $0.0 \%$ & $0.0 \%$ & $0.0 \%$ & $0.0 \%$ & $9.6 \%$ & $0.0 \%$ \\
\hline
\end{tabular}

In contrast, the 18-30 year age group had no idea of bonobo abundance. However, notes from several focus group sessions indicated that the term 'abundance' caused people to think of group sizes 
rather than population size. By 'abundant', some respondents meant bonobo groups of $15-20$ individuals.

To questions about whether 'bonobos have ever been present, if they were present, how long ago was that and if they have been present in the past, why are they no longer there?' Most (88.4\%) respondents thought these questions lacked sensibility because bonobos have always been part of their immediate environments while $9.6 \%$ thought that bonobos were extinct in their environment 20 years ago.

Answers differed among age groups (Table 2). Only $35 \%$ of younger people from 18-30 years of age felt that they might encounter bonobos within 3hour walk while fewer $(20 \%)$ older people (> 45 years old) felt the same way (Table 2). Furthermore, only younger people reported having seen bonobos at distances > 4-hour walk in the forest. Equally important was the perception of abundance among different age groups. Adults from $30-45$ years of age were the only age group that reported bonobos to be very abundant and abundant. In contrast, the older age group felt that bonobos have become rare, while the younger group had no clear view of bonobo abundance.

Some interviewees reported that bonobos had disappeared from their area, principally villagers from Tshumbiri (ca. $80 \mathrm{~km}$ from Malebo), who indicated that the principal cause of bonobo loss was deforestation (39\%), followed by human population growth $(21 \%)$. In contrast, hunting pressure $(11 \%)$ came only fourth after logging (18\%). However, if logging (18\%) was combined with the general deforestation category (39\%), villagers perceive habitat loss as the most important threat facing bonobos.

Most $(94.5 \%)$ respondents, regardless of village, reported having seen bonobos at least once in their lifetime (Table 3). Among those who had seen bonobos, most $(61.6 \%)$ had seen bonobos very often, but could not specify on how many occasions.

Some $27.4 \%$ of respondents claimed that they had seen either captured bonobos in the forest far from their villages, or when bonobos were still numerous around their villages. Most respondents (60.1\%) reported having met bonobos in groups that numbered from 6-15 of individuals (Table 2).

Most (61.6\%) respondents from Bateke said they had seen bonobos eating fruits, while some (34.3\%) respondents said that bonobos ate leaves (Table 3 ). Responses to the question of what species of animal, fish and insects respondents thought bonobos ate included: shrimps (36.8\%); worms (34.2\%), crabs $(18.4 \%)$, undistinguished fish $(5.3 \%)$, and blue duikers $(2.6 \%)$.

Table 3 Numbers of bonobos sighted by respondents during their lifetime, numbers of individuals often sighted in a group and plant parts eat by bonobos

\begin{tabular}{lrlrlr}
\hline \# Sightings of bonobos & \multicolumn{2}{l}{ \# of individuals sighted/group } & \multicolumn{2}{l}{ Part of trees and food items } \\
\hline Never seen & $4.8 \%$ & $1-5$ Individuals & $12.3 \%$ & Fruits & $61.6 \%$ \\
$1-5$ times & $26.0 \%$ & $6-10$ Individuals & $32.2 \%$ & Leaves & $34.3 \%$ \\
$6-10$ time & $2.7 \%$ & $10-15$ individuals & $32.9 \%$ & Stems & $2.7 \%$ \\
$>10$ times & $4.1 \%$ & $>15$ individuals & $4.1 \%$ & Meat & $0.0 \%$ \\
Many times & $61.6 \%$ & Many individuals & $15.1 \%$ & Insects & $0.7 \%$ \\
N/A & $0.68 \%$ & N/A & $3.4 \%$ & Others & $0.7 \%$ \\
\hline
\end{tabular}

Results on the traditional hunting for the bonobos from the two ethnic groups and the cosmopolitan areas indicated that most people in the southern Lake Tumba Landscape had not historically hunted bonobos as most answers (89\%) indicated (Figure 2). Among the $89.0 \%$ of respondents who thought that bonobos had not been hunted in the past, most $(63.01 \%)$ thought that bonobos were not hunted historically in their villages because of traditional taboos and 5\% thought that this attitude was dictated by the fear of traditional chiefs (Figure 2). Because obedience to the authority of traditional chiefs is itself a taboo, it is therefore logical to say that ca.
$70 \%$ of respondents thought that bonobos were not hunted because of traditional taboos. Among the $11.0 \%$ who said that bonobos were killed historically, $69.9 \%$ thought bonobos were killed accidentally and the remaining $30.1 \%$ thought bonobos were killed for cultural events such as sacrifices (Figure 2). When asked about the present day situation, respondents indicated that cultural patterns in bonobo hunting had shifted: $51.0 \%$ said bonobos were presently hunted and mostly (37.7\%) for money (Figure 2). There are two noticeable changes in comparing the historical and current patterns: (i) the introduction of both meat and money as cause for hunting bonobos, and (ii) the 
end to killing bonobos for traditional cultural events. A comparison of what most protects bonobos shows that traditional taboos were equally important in the past $(63.0 \%)$ as they are in present day $(68.5 \%)$.
However, fear of modern conservation law is only regarded as important by $6.9 \%$ of people in the present day (Figure 2).

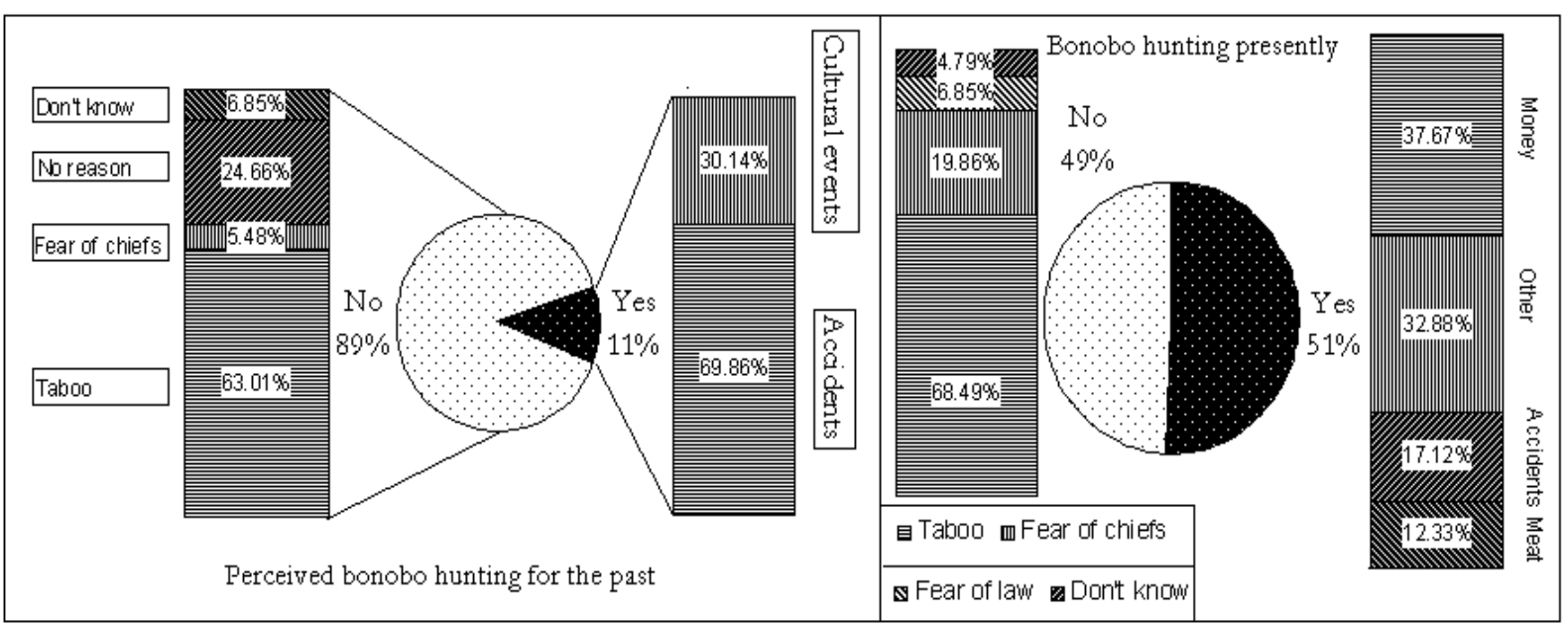

Figure 2 Perceived hunting for bonobos: Past and present in the southern Lake Tumba Landscape.

Almost all ( 92\%) respondents agreed that they had been informed of the conservation status of bonobos, and most $(78.8 \%)$ noted they had been informed increasingly frequently in the last five years. This information was mainly provided by conservation organizations $(62.3 \%)$, followed by state institutions $(14.3 \%)$, traditional authorities $(10.3 \%)$ and churches $(7.5 \%)$ (Figure 3$)$.

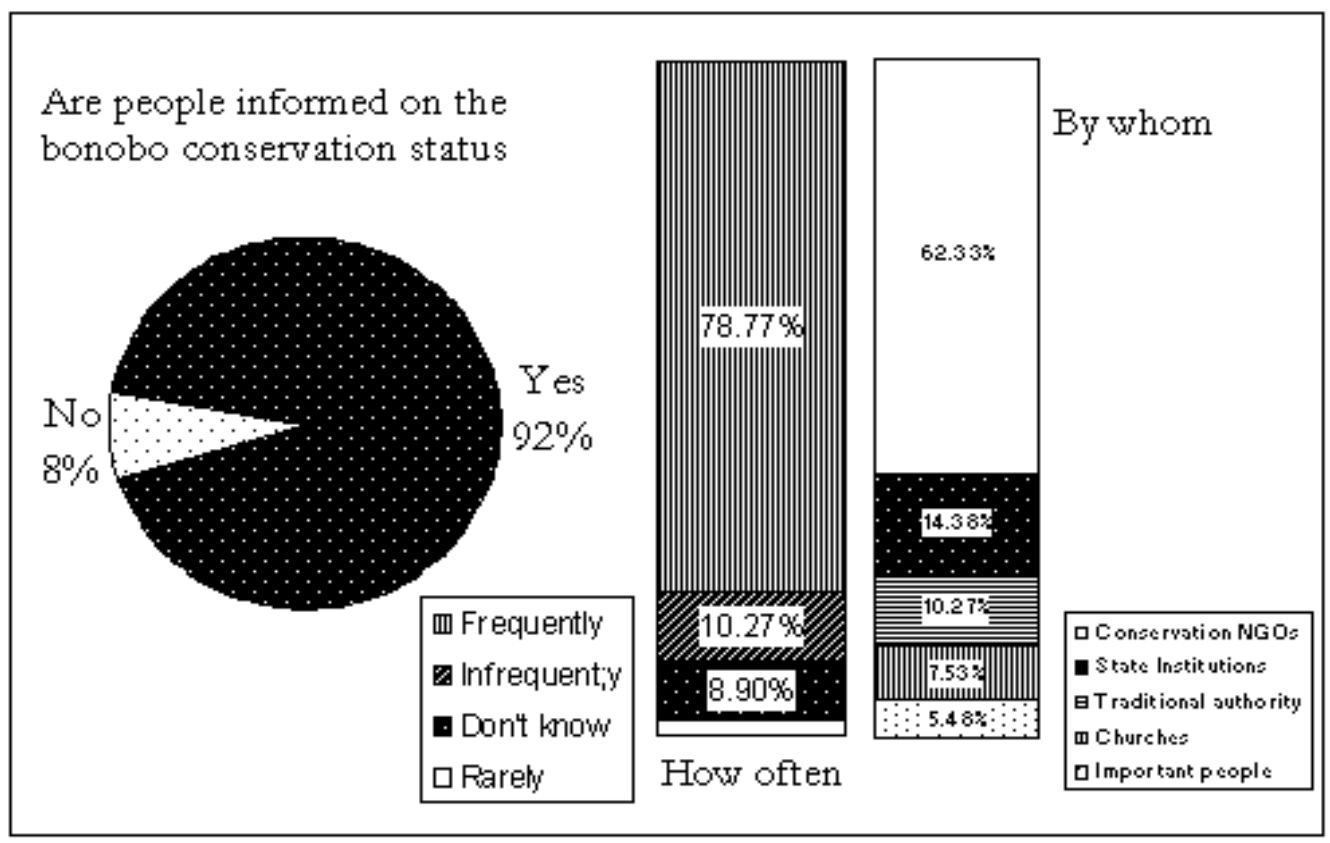

Figure 3. Local people and information on conservation of bonobos in the southern Lake Tumba landscape 
Equally, most (70\%) respondents indicated that the conservation of bonobos had long been part of their social education process, pre-dating current conservation efforts by the government and different conservation non-governmental organizations, whether foreign, national or local.

\section{Discussion}

Differences in answers per age groups between younger people (18 - 30 years old), mature people $(30-45$ years old) and old people (>45 years old) may be explained in different ways. Differences felt in walking distance to where bonobos actually occur may be due to the physical strength, younger people being able to travel more rapidly than older groups. This may also explain why it was only younger people that reported longer distances > 4-hour walk in the forest. However, the perception of the abundance may be related to activities carried out by different age groups. Younger people lack of perspectives on the trends of the bonobo populations may simply reflect either their lack of interest in traditional activities such as traditional hunting, cultivating fields for families, etc. In this sense, more adults $(30-45$ years old) answered questions related to the abundance of bonobos may reflect only their continuous contacts with forests where they are actively involved in hunting, cultivating and fishing. It was surprising that only the people belonging to the oldest age group felt that bonobos decreased in the last decades. This felt decrease in the bonobo population by the oldest group ( $>45$ years old) could be due to the fact that this group no longer goes to the deep forest as frequently as the younger groups, and therefore may have a stained vision of the actual reality. However, it may also be simply that either the younger age or the mature age groups do not have a historical memory of the past bonobo populations in the region. Therefore, the old age group would be using the historical memory that it possesses to compare the actual populations of bonobos against what they used to see in the recent past. The discrepancies in different perceptions hold by different age groups in their assessment of the bonobo populations is in alignment with the general trend over many other issues in most of the African culture.

Loss of traditional knowledge and shifting baselines have been described in Dzanga-Sangha, Central African Republic (Hardin \& Remis, 2006) and in other cultures around the world (Sáenz-Arroyo et al. 2005). Younger generations no longer believe in historical anecdotes of past distribution or abundance (Sáenz-Arroyo et al. 2005), which in turn reinforces observed changes in baselines compared to environmental assets and their current status. It has been argued that colonisation, education, urbanization and globalization brought to a cultural erosion phenomenon where by traditional knowledge is being lost (Brosi et al., 2007; Benz et al., 2000).

Local communities are acutely aware of the major threats facing biodiversity in their local area. Growth in human populations, deforestation, habitat fragmentation (Hill \& Curran, 2005; Chapman \& Lambert , 2000) due to logging and other human extractive activities are known to be the root-causes for declining biodiversity all over the world (Dale \& Slembe, 2005) IUCN Red List Analyses.

Most respondents claimed to have seen bonobos (Table 3) and possess knowledge about the numbers of individuals they have sighted (Table 3), in the past or recently, in a region where bonobos were only described for science in 2007. Previous studies of bonobo distribution (Kano, 1984; Fenart \& Deblock, 1973) inferred their presence in the vicinity of Lake Tumba, but bonobos were never thought to be present around Malebo (Inogwabini et al., 2007a; Inogwabini et al., 2000b), which was thought to be a marginal habitat. Local knowledge bonobos around Malebo shows how little the conservation community may really know about biodiversity in DRC, and suggests ways in which knowledge could be more thoroughly and inexpensively described. The overlap between the fresh nest count techniques, which is very often used to provide estimates of group sizes in great apes (Hall et al., 1998; Fruth \& Hohmann, 1994), and the local knowledge, may help improve our understanding of the current and past distributions of some icons of the biodiversity conservation in Africa. Debate over the accuracy and the role that local and indigenous knowledge has to play in documenting biodiversity, and in implementing conservation policies, has very often suffered because there is no hard evidence to support their relevance (Colding \& Folke, 2001; Berkes et al., 2000), which this study undoubtedly provides.

Linkages between local knowledge and scientific enquiries have started to emerge from other areas of research in Africa (Redford \& Fearn, 2007; Bauer, 2003) and other traditional societies (Colding \& Folke, 2001; Berkes et al., 2000; Berkes, 1998; Gadgil et al., 1993). Our current knowledge of species diversity and distribution patterns is still limited (Cordeiro et al., 2007), and species (and sometimes genera) of plants, birds, amphibians, reptiles, invertebrates and even mammals may disappear before they are actually described for science. Therefore, the extensive overlap between answers provided by local communities and formal scientific surveys implies that, within certain limits and provided that proper triangulation is carried out, that local information should be taken seriously and 
help guide conservation planning and activities for the bonobos in the region of Malebo. Indeed, the Convention on Biological Diversity recognises the close inter-dependence of traditional and local communities on biological resources. Indeed, Article 8(j) called on parties to respect, preserve, and maintain traditional knowledge relevant for the conservation and sustainable use of biodiversity (Redford \& Fearn, 2007).

Local communities noted that hunting taboos had changed following the introduction of money (Figure 2), and known to be one of the most important drivers of major changes in human history, that in turn has brought about deeply felt changes to traditional lifestyles and traditional economic systems (Bohannan, 1959). Alterations in traditional lifestyles and economic systems in their turn have tailored perceptions that people have strongly cherished mechanisms for sharing and ensuring collective social security in Africa (Kitanishi, 2006; Turnbull, 1973). This is particularly important in regions where the 'monetarization' processes has been accompanied by the acquisition of new tools or technologies, which is now the case in almost all extant cultures. A hidden factor, not directly cited by interviewees is the access to new weapons for hunting, particularly the introduction of guns, which was described during focus group sessions as causing most accidental killing of bonobos. Furthermore, hunting for money and commerce has replaced the nascent economic activities left behind by the Belgians during colonial times, when they promoted trade in agricultural products such as coffee, palm oil, rubbers, which fulfilled local people's emerging needs in cash and modern commodities (Inogwabini et al. 2007b). However, after nationalization of the economy in 1972, the market system broke down and seriously affected transport infrastructure, leading to a severe decline in agricultural activities across the entire southern Lake Tumba landscape region. After several years of economic and political chaos, recourse to natural resources through hunting and fishing became the easiest and only way for most people to earn monetary income. Despite difficulties in transportation, the bushmeat trade became an extraordinary organized activity, pioneered by social hierarchies based in the main towns. Intensive bushmeat trade to supply big towns and other markets spread over the southern Lake Tumba landscape region. As was the case in most of Central African forests (LeBreton et al., 2006; Cowlishaw, et al., 2005; Wilkie et al., 2005; De Merode et al., 2004; Fa et al., 2003; Wilkie et al., 2000; Wilkie et al., 1992), wildlife populations became depleted from many parts of the landscape. Therefore, even mythical species like bonobos were hunted by ethnic groups where the species had not previously been hunted. This clearly explains why local communities believe on-going poaching of bonobos is mostly driven by trade to make money, and only to a lesser extents for other reasons such as cultural events or pure accidents.

Another major shift is the present extent to which bonobos are hunted for meat (Figure 2). This shift may be due to immigration into the region, in which newly established ethnic groups have introduced a culture that excludes taboos on hunting bonobos.. In the cosmopolitan village of Mbazi, most people belong to the Ngando ethnic groups which straddles across the province of Equateur and the Province Oriental, about $800 \mathrm{~km}$ straight-line distance north-east of their actual location. Indeed, most answers that acknowledged the hunting of bonobos were gathered from similarly cosmopolitan areas such as Tshumbiri, Bolobo and Lebomo. Other explanations for this change might include the increasing requirement for protein among local communities. This result clearly highlights that a crack now runs through the traditional cultural system. In fact, with all new developments, involving massive movements of people of different cultures and in communication technologies, nothing is left that could be called 'immaculate culture', not even in previously remote areas or even previously unshakable cultures such as those described in Conrad's hearts of darkness and, generally, Thoreau's Thorstein Veblen.

Taboos and other traditional institutions have played key roles in preserving endangered species in many areas around the world, including Madagascar (Lingard et al., 2003). Most respondents in the southern Lake Tumba landscape thought bonobos were well protected, both currently and in the past, by traditional taboos and by recognition of traditional authority (Figure 2).

Furthermore, $<10 \%$ of respondents claimed that existing legal laws were the motive for not hunting bonobos (Figure 2). Given that the southern Lake Tumba landscape (Inogwabini et al., 2007a; Inogwabini et al. 2007b) has held $\sim 20 \%$ of the wild population without prior intervention by conservation managers or scientists (Inogwabini et al. 2007a), taboos and the place of local traditional authority should be recognized as a successful way to manage and protect this critical population of bonobos. Therefore, conservation organizations should be encouraged to incorporate local knowledge, traditional taboos and the local traditional authority in future law enforcement schemes.

\section{Conclusion}

This study showed that local communities may have critical knowledge of biodiversity in their forests and 
that local ecological knowledge of species ecology and ways in which species are perceived by different tribes influence communities' willingness to protect species. More generally, we concluded that to address conservation issues, conservation research should include efforts to gather data on local ecological knowledge and historical and cultural usages of habitats and species together with ecological research to craft sound conservation action plans.

\section{Acknowledgements}

Fieldwork was conducted as part of the WWF Lac Tumba Program through the founding from the Central African Regional Program for Environment (CARPE) of the US Agency for International Development. However, views expressed here are those of the authors and do not reflect those of the USAID or the US Government. We would like to thank our field teams that participated in the collection of the data. The writing up of this paper has been made possible by the Postdoctoral Grant received by Bila-Isia Inogwabini from the Department of Aquatic Sciences and Assessment, Swedish University of Agricultural Sciences, Uppsala.

\section{References}

Anka, Z., Seranne, M., di Primio, R., Scheck-Wenderoth, M. ( 2007). Evidence and implications of an upper-Cretaceous deep-sea fan on the Abyssal Plain of the Congo-Angola basin. Geophysical Research Abstracts. Vol 9, Abstract № 02785.

Badrian, N.L. \& Malenky, R.K. (1984). Feeding ecology of Pan paniscus in the Lomako forest, Zaire. In Susman, R.L. (Editor). The Pygmy chimpanzee: evolutionary biology and behavior. Plenum Press. New York, United States of America: 325 - 346.

Bailey, R.G. (1986). The Zaïre River system. In R. Davies \& K.F. Walker (Editors). The Ecology of River Systems. Junk Publishers. Dordrecht, The Netherlands: 201-214.

Barnes, R.F.W., Barnes K.L., Alers M.P.T. \& Blom, A. (1991). Man determines the distribution of elephants in the rain forests of northern Gabon. African Journal of Ecology. 29,5463.

Bauer, H. (2003). Lion conservation in west Africa: integrating social and natural science for wildlife conflict resolution around Waza National Park, Cameroon. Ph.D. Thesis. Leiden University. Leiden, the Netherlands.

Bennett, E.L. \& Robinson, J.G. (2000). Hunting of wildlife in tropical forests implications for biodiversity and forest peoples. The World Bank Environment Department. Biodiversity Series - Impact Studies. Paper 76.

Benz, B. F., J. Cevallos, Santana, F., Rosales, J. \& Graf, S. (2000). Losing knowledge about plant use in the Sierra de Manantlan biosphere reserve, Mexico. Economic Botany. 54, 183-191.

Berkes, F. (1998). Indigenous knowledge and resource management systems in the Canadian subarctic. In Berkes, F. \& Folke, C. (Editors). Linking social and ecological systems. Management practices and social mechanisms for building resilience. Cambridge University Press. Cambridge, United Kingdom: 98-128.

Berkes, F., Colding, J. \& Folke, C. (2000). Rediscovery of traditional ecological knowledge as adaptive management. Ecological Applications. 10, 1251-1262.

Bohannan, P. (1959). The Impact of money on an African subsistence economy. The Journal of Economic History. 19 491-503.
Boitani, L. (1995). Ecological and cultural diversities in the evolution of wolf-human relationship. In Carbyn, L.N., Fritts, S.H. \& Seip, D.R. (Editors). Ecology and conservation of wolves in a changing world. Canadian Circumpolar Institute. Edmonton, Canada: 3 - 12.

Brncic, T., Menga P., \& Lejoly, J. (2007). Preliminary report of botanical activities carried out in the Lac Tumba Landscape, DRC January - February 2007. Submitted to the World Wide Fund for Nature, Kinshasa Office Democratic Republic of Congo.

Brosi, B.J., Balick, M.J., Wolkow, R., Lee, R., Kostka, M., Raynor, W., ... Ling, D.L. (2007). Cultural erosion and biodiversity: canoe-making knowledge in Pohnpei, Micronesia. Conservation Biology. 21, 875-879.

Butynski, T.M. \& Sarmiento, E. (1996). The gorillas of the Mt. Thsiaberimu, Zaire. Gorilla Conservation News. 10, $10-15$.

CBFP (Congo Basin Forest Partnership). (2005). The forests of the Congo Basin: A preliminary assessment. The Untied States Agency for International Development (USAID). Washington DC, United States of America.

Chapman, C. \& Lambert J. E. (2000). Habitat alteration and the conservation of African primates: case study of Kibale. American Journal of Primatology. 50, 169-285.

Clarke, G.M. (1994). Statistics and experimental design: an introduction for biologists and biochemists. $3^{\text {rd }}$ Edition. Arnold. London, United Kingdom.

Colding, J. \& Folke, C. (2001). Social taboos: Invisible systems of local resource management and biological conservation. Ecological Applications. 11, 584-600

Cordeiro, N. J., Burgess, N. D., Dovie, D. B. K., Kaplin, B. A., Plumptre, A. J. \& Marrs, R. (2007). Conservation in areas of high population density in sub-Saharan Africa. Biological Conservation. 13, $155-163$.

Corsi, F., (1984). Développement et aménagement des pêches du Lac Mai Ndombe et ses affluents. Food Aid Organization (FAO)/Programme des Nations Unies pour le Développment (PNUD). Projet FAO-PNUD/ZAI/80/003. Document de Travail 1.

Cowlishaw, G., Mendelson, S. \& Rowcliffe, M.J. (2005). Structure and operation of a bushmeat commodity chain in southwestern Ghana. Conservation Biology. 19, 139-149.

Dale, S. \& Slembe, B. (2005). Effects of selective logging (50 years ago) on habitat use and ranging behaviour of a forest understorey bird (red-tailed bristlebill, Bleda syndactyla) in Uganda. African Journal of Ecology. 43, 114-122

De Merode, E., Homewood, K. \& Cowlishaw, G. (2004). The value of bushmeat and other wild foods to rural households living in extreme poverty in Democratic Republic of Congo Biological Conservation. 118, 573-581.

Ennos, R. (2000). Statistical and data handling skills in Biology. Pearson \& Prentice Hall. Edinburgh, United Kingdom.

Fa, J.E., Currie, D. \& Meeuwig, J. (2003). Bushmeat and food security in the Congo Basin: linkages between wildlife and people's future. Environnemental Conservation. 30, 71-78.

Fenart, R. \& Deblock, R. (1973). Pan paniscus et Pan troglodytes : craniométrie - étude comparative et ontogénique selon les méthodes classiques et vestibulaire (I). [Pan paniscus and Pan troglodytes: a comparative study of skull and ontogeny using classic methods]. Annales du Musée Royale de L'Afrique Centrale. Série 8-Sciences Zoologiques. 204, 1-473.

Fruth, B. \& Hohmann, G. (1994). Comparative analysis of nest building behavior in bonobos and chimpanzees. In Wrangham, R.W., M'Grew, W.C., De Wall, F.B.M. \& Heltne, P.G. (Editors). Chimpanzee cultures. Harvard University Press. Cambridge, United States of America: 109 - 128.

Gadgil, M., Berkes, F. \& Folke, C. (1993). Indigenous knowledge for biodiversity conservation. Ambio. 22, 151-156.

Gadsby, E. L. (1990). The status and distribution of the drill (Mandrillus leucophaeus) in Nigeria. Report to Wildlife Conservation International, WWF (United States of America) 
\& WWF (United Kingdom) and the Nigerian Government. Typescript unpublished report.

Gautier-Hion, A., Colyn, M. \& Gauthier, J.P. (1999). Histoire naturelle des primates d'Afrique Centrale. Ecosystèmes d'Afrique Centrale (ECOFAC) - Union Douanière et Economique d'Afrique Centrale (UDEAC) Multipress. Libreville, Gabon.

Hall, J.S., White, L., J., T., Inogwabini, B.I., Omari, I., Morland HS, ... Freeman, K. (1998). A survey of the Grauer's gorilla (Gorilla gorilla graueri) and eastern chimpanzee (Pan troglodytes schweinfurthi) in the Kahuzi-Biega National lowland sector and adjacent forests in Eastern Democratic Republic of Congo. International Journal of Primatology. 19, $207-235$.

Hardin, R. \& Remis, M.J. (2006). Biological and cultural anthropology of a changing tropical forest: a fruitful collaboration across subfields. American Anthropologist. $108,273-285$.

Hill, J.L. \& Curran, P.J. (2005). Fragment shape and tree species composition in tropical forests: a landscape level investigation. African Journal of Ecology. 43, 35-43.

Hulstaert, G. (1993a). Etudes dialectologiques Mongo - [Studies of the Mongo dialects]. Etudes Aequatoria. 12: 15 - 4006.

Hulstaert, G. (1993b). Liste et carte des dialectes Mongo - [Map and list of the Mongo dialects]. Annales Aequatoria. Volume 14: $401-406$.

Ilersic, A.R. (1973). Statistics. $13^{\text {th }}$ Edition. HFL Publishers LTD. London, United Kingdom.

Inogwabini, B.I. (2013). The Lake Télé - Lake Tumba Landscape. In Howarth, R.W. (Editor). Biomes and Ecosystems: An Encyclopaedia. Salem Press \& Golson Media: 749 - 751.

Inogwabini, B.I. (2010). Conserving great apes living outside protected areas: the distribution of bonobos in the LakeTumba landscape, Democratic Republic of Congo. Thesis submitted for the Degree of Doctor of Philosophy in Biodiversity Management. Durrell Institute of Conservation and Ecology, University of Kent at Canterbury, UK.

Inogwabini, B.I. \& Thompson, J.A.M. (2013). The Golden-bellied Mangabey (Cercocebus chrysogaster): distribution and conservation status. Journal of Threatened Taxa. http://dx.doi.org/10.11609/JoTT.03185.4069-75"

Inogwabini, B.I. \& Leader-Williams, N. (2012). Using the Keywords to Explain the Bonobo Distribution as an Effect of Human Perception of the Species. American Journal of Human Ecology. 1, 102 - 110.

Inogwabini, B.I. \& Bewa, M. (2009). Bonobo food items, food availability and bonobo distribution in the Lake Tumba Swampy forests, Democratic Republic of Congo. The Open Conservation Biology Journal. 3, 1 - 10.

Inogwabini, B.I., Sandokan, M.B. \& Ndunda, M. (2006). A dramatic decline in rainfall regime in the Congo Basin: evidence from a thirty-four year data set from the Mabali Scientific Research Centre, Democratic Republic of Congo. The International Journal of Meteorology 31(312), 278- 285.

Inogwabini, B.I., Omari, I. \& Mbayma, A.G. (2005). Protected areas of the Democratic Republic of Congo. Conservation Biology. 19, 15-22.

Inogwabini, B.I., Bewa, M., Mbende, L. Abokome, M. \& Tshimanga, W.T (2007a). The great apes in the Lac Tumba landscape, Democratic Republic of Congo: newly described populations. Oryx. 41, 532-538

Inogwabini, B.I., Bewa. M., Mbende, L., Abokome, M. \& Miezi, V. (2007b). The Bonobos of the Lake Tumba - Lake Maindombe Hinterland: Threats and Opportunities for Population Conservation. In Furuichi, T. \& Thompson, J. (Editors). The bonobos: behavior, ecology, and conservation. Springer. New York, United states of America: 273-290.

INS (Institut National des Statistiques). (1984). Recensement scientifique de la population 1984: Zaire et régions 1984 2000. Ministère du Plan et Aménagement du Territoire, Kinshasa, République du Zaïre.

Kano, T. (1984). Distribution of Pygmy chimpanzees (Pan paniscus) in the Central Zaire Basin. Folia Primatologica. $43,36-52$.

Kitanishi, K. (2006). The impact of cash and commodization on the Baka hunter-gatherer society in southeastern Cameroon. African Study Monographs - Supplement. 33, 121-142

LeBreton, M. ., Prosser, A. T., Tamoufe, U., Sateren, W., MpoudiNgole, E.., ... Wolfe, N. D. (2006). Patterns of bushmeat hunting and perceptions of disease risk among central African communities. Animal Conservation. 9, 357-363.

Lingard, M., Raharison, N., Rabakonandrianina, E., Rakotoarisoa, J.A. \& Elmqvist. T. (2003). The role of local taboos in conservation and management of species: the radiated tortoise in Southern Madagascar. Conservation and Society. Retrieved from: http://www.conservationandsociety.org /c_s_1_2-3-marlene.pdf.

Morris, B. (2000). The power of the animals: An ethnography. Oxford University Press. Oxford, United Kingdom.

Peters, C.R. \& O’Brien, E. (1999). Palaeo-lake Congo: implications for Africa's late Cenozoic climate - some unanswered questions. Proceedings of the $\mathrm{XV}^{\text {th }}$ INQUA Conference, Durban, South Africa, 3-11 August 1999. Palaeoecology of Africa and Surrounding islands. 27: $11-18$.

Redford, K.H. \& Fearn, E. (2007). Protected areas and human displacement: a conservation perspective. The Wildlife Conservation Society. Working Papers 29. New York, United States of America.

Sáenz-Arroyo, A., Roberts, C.M., Torre, J., Cariňo-Olvera, M. \& Enríquez-Andrade, R.R. (2005). Rapidly shifting environmental baselines among fishers of the Gulf of California. Proceedings of the Royal Society B. 272, 19571962.

Sokal, R.R. \& Rohlf, F. J. (1995). Biometry. $3^{\text {rd }}$ Edition. Freeman \& Cie. New York, United States of America \& Oxford, United Kingdom.

Turnbull, C.H. (1973). Africa and Change. Alfred A. Knopf. New York, United States of America

Wilkie, D.S., Starkey, M., Abernethey, K., Effa, E.N., Telfer, P. \& Godoy, R. (2005). Role of prices and wealth in consumer demand for bushmeat in Gabon, central Africa. Conservation Biology. 19, 268-274.

Wilkie, D., Shaw, E., Rotberg, F., Morelli, G. \& Auzel, P. (2000). Roads, development, and conservation in the Congo Basin. Conservation Biology. 14, 1614-1622.

Wilkie, D.S., Sidle, J.G. \& Boundzanga, G.C. (1992). Mechanized logging, market hunting, and a bank loan in Congo. Conservation Biology. 6, 570-580. 